\title{
LA AMBIGÜEDAD LEGISLATIVA COMO PRÁCTICA PARLAMENTARIA: LA IGLESIA CATÓLICA Y LA LEY DE IGLESIAS EN SU ARTÍCULO 20
}

\author{
Jorge Enrique Precht Pizarro ${ }^{1}$
}

SUMARIO: Introducción. 1.- La ambigüedad en la Cámara de Diputados. Primer trámite constitucional. 2.- La ambigüedad en la Comisión Especial del Senado. Segundo trámite constitucional. 3.- La ambigüedad en la Comisión de Constitución del Senado. 4.- La ambigüedad en la Sala del Senado. Segundo trámite constitucional. 1.- La ambigüedad en la Cámara de Diputados. Tercer trámite constitucional. A modo de epilogo.

\section{INTRODUCCION}

Se ha estado alabando en nuestro medio la ambigüedad como una virtud política. Tal ambigüedad -que no es sino una consecuencia del relativismo valóricose ha hecho una práctica legislativa corriente como expresión de acuerdos parlamentarios que poco tienen de consenso y mucho de juegos venecianos. El caso del proyecto de ley sobre constitución y organización jurídica de las iglesias y otras organizaciones religiosas nos da un ejemplo palmario de este fenómeno.

\section{1.- LA AMBIGÜEDAD EN LA CÁMARA DE DIPUTADOS. PRIMER TRÁMITE CONSTITUCIONAL.}

Con el objeto de respetar el régimen jurídico y los derechos adquiridos de las iglesias que gozan de personalidad jurídica de derecho público, el Gobierno del Presidente Aylwin excluyó a estas iglesias particulares de la Iglesia Católica, de la aplicación de la ley de una manera clara y directa: "Las normas de esta ley no serán aplicables a las personas jurídicas a que se refiere el inciso segundo del artículo 547 del Código Civil" (27 de octubre de 1993).

Así lo aprobó la Comisión de Derechos Humanos de la Cámara. Se lee en la página 15 del Informe de 9 de Agosto de 1995 de la Comisión de Derechos Humanos, Nacionalidad y Ciudadanía de la Cámara de Diputados: "La Comisión aprobó el inciso quinto del artículo $1^{\circ}$ en los términos propuestos en el Mensaje, considerando en especial que la condición jurídica actual de la Iglesia Católica se ha establecido tanto, por principios doctrinarios como por la jurisprudencia que han sostenido unánimemente que el texto del artículo 547, inciso segundo, ya citado, del

Abogado. Doctor en Derecho y en Ciencia Política. Profesor titular de Derecho Público, Pontificia Universidad Católica de Chile, 
Código Civil, se aplica con la exclusividad a la Iglesia Católica, tesis que los representantes de dicha confesión declararon compartir y reafirmaron ante la Comisión, quedando en consecuencia fuera de los alcances de este proyecto". Firmaron este informe los diputados Gabriel Ascencio, Presidente; Andrés Aylwin, Guillermo Ceróni, Andrés Chadwick; Alejandro García Huidobro; Jaime Naranjo; Sergio Ojeda; Vicente Sota; Alfonso Vargas y Erich Villegas.

La exclusión de la Iglesia Católica también la había hecho el proyecto de ley iniciado por moción del Senador Frei Bolívar el 8 de septiembre de 1993, cuyo artículo primero inciso segundo decía: "Las normas de esta ley no le serán aplicables a las iglesias y comunidades religiosas a que se refiere el inciso $2^{\circ} \mathrm{del}$ art. 547 del Código Civil" y cuyo artículo segundo, inciso segundo expresaba; "Toda vez que esta ley emplee los términos "organización" o "entidad", se está refiriendo a "iglesias u organizaciones cristianas evangélicas". Firman copatrocinando esa moción los Senadores Mario Ríos Santander, Laura Soto González, Arturo Frei Bolivar y Mario Papi Beyer. Así también lo hacía la moción (Boletín 649 - 07) del diputado Edmundo Salas cuyo artículo 3 decía: "Las Iglesias Evangélicas que se establezcan en el futuro gozaran de personalidad jurídica de derecho público..." (1993).

Pero, sometido el proyecto a la Comisión de Constitución de la Cámara una indicación substitutiva de origen parlamentario efectuó una mutación del proyecto titulado ideológicamente ahora " ley marco de libertad religiosa" y luego "ley marco de igualdad religiosa" y conocida más tarde como "ley de Cultos".

El autor de esta indicación substitutiva fue el diputado don Sergio Elgueta, ampliamente felicitado por sus colegas a través de todo el trámite legislativo. La verdad sea dicha, en ámbito académíco por lo menos: tal indicación es una copia de la normativa española. El artículo primero es igual al $1^{\circ}$ de la Ley española de 5 de julio de 1960 , el concepto de entidad religiosa es copiado del artículo $1^{\circ}$ del Real Decreto 142 de 1981, el artículo segundo transitorio es igual a la segunda disposición transitoria, el artículo $6^{\circ}$ es igual al segundo español; el noveno es igual al quinto y suma y sigue.

Así las cosas. el inciso final del artículo primero del proyecto Aylwin fue substituido por la disposición primera transitoria española de 5 de julio de 1980 , insertándola en el proyecto chileno como artículo primero transitorio.

No tomó en cuenta el diputado antedicho que la Constitución Española hace referencia explícita a la Iglesia Católica en el artículo 16, a línea 3: "Ninguna confesión tendrá carácter estatal. Los poderes públicos tendrán en cuenta las creencias religiosas de la sociedad española y mantendrán las consiguientes relaciones de cooperación con la Iglesia Católica y las demás confesiones". Como se sabe, el Estado español estipuló 4 acuerdos con la Santa Sede, entre ellos uno sobre asuntos jurídicos el 3 de enero de 1979 y ya el 28 de julio de 1976 un acuerdo básico con la Iglesia Católica. Todo ello está vigente el 5 de julio de 1980 cuando se 
dicta la Ley Orgánica española de donde se extrae una norma que queda sin sentido al transportarla a Chile.

La indicación Elgueta es el comienzo del viaje a la ambigüedad: "El Estado reconoce la personalidad jurídica y la plena capacidad de obrar de las entidades religiosas que gocen de ella a la fecha de entrada en vigencia de la ley". Así fue aprobado en primer trámite por la Sala de la Cámara de Diputados.

Dejo de lado la iatrogenia que produce este injerto hispánico en el tejido normativo chileno, dejo de lado la imperfecta redacción (si el artículo se refiere a la personalidad y a la capacidad debió decir que gocen de "ellas"), olvido incluso que la categoría "capacidad de obrar" no es utilizada en nuestro medio. En efecto, el Código Civil español, siguiendo a Savigny, distingue entre capacidad de obrar y capacidad jurídica, pero no lo hace nuestro Código Civil. (Para aproximarse al tema véanse artículos: "Capacidad, capacidad jurídica, capacidad de obrar en "Enciclopedia Jurídica Básica", Civitas, Madrid. 1995. Igualmente la obra de Enrique Ramos Chaparro: "La persona y su capacidad civil". Tecnos. Madrid. 1995, páginas 196-207).

Procedo a demostrar las múltiples dificultades que genera en nuestro medio la copia del texto español.

El ambiguo artículo dice que: "El Estado reconoce...". No se divisa cuál sea el asidero constitucional de esta expresión ya que es la propia Constitución la que ha reconocido a la Iglesia Católica desde el Reglamento Provisional del 1811 y respecto de "iglesias, confesiones e instituciones religiosas" es de suponer que el artículo $10 \mathrm{~N}^{\circ} 2$ de la Constitución de 1925 (actual $19 \mathrm{~N}^{\circ} 6$ ) implícitamente ya les reconoce a dichas entidades algún tipo de personalidad puesto que las habilita (a lo menos a las confesiones religiosas) "para erigir y conservar templos y sus dependencias bajo las condiciones de seguridad e higiene fijadas por las leyes y ordenanzas".

Por lo tanto, no se ve cuál es la utilidad de reconocer en sede legislativa lo que está reconocido en sede constitucional; y no se ve la utilidad que sea el Estado el que reconozca lo que en sede más elevada - la Constitución de la República - ha sido ya consagrado. Ni se ve cómo el Estado puede ser "garante de libertad religiosa" como dice el artículo $1^{\circ}$ del proyecto, si se lee el artículo $7^{\circ}$ de la Constitución de 1980.

Ahora bien, el ambiguo texto propuesto por la Cámara de Diputados se refiere a todas las entidades religiosas. Las había en este momento con personalidad jurídica de derecho público y con personalidad de corporación o fundación de derecho privado. Todas ellas son reconocidas. Pero: ¿ Se les aplica o no en el futuro la presente ley?. Si se crea un nuevo ente religioso por una iglesia ya reconocida por este artículo: ¿debe hacerlo conforme a esta ley o conforme a las disposiciones que la rigen? 
Si aparece una nueva iglesia: ¿Puede constituirse como personalidad jurídica de derecho público o corporación privada o sólo debe hacerlo conforme a la nueva ley?

Se les reconoce a las entidades religiosa la plena capacidad de goce y ejercicio (si traducimos a lo nuestro la mentada "capacidad de obrar"). Ahora bien: ¿Qué sucede si la legislación ha creado incapacidades para determinadas iglesias? ¿Se mantienen o quedan derogadas? ¿Se deroga, por ejemplo, el artículo 965 del Códígo Civil: "Por testamento otorgado durante la última enfermedad no puede tecibir herencia o legado alguno, ni aún como albacea fiduciario; el eclesiástico que hubiere confesado al difunto durante la última enfermedad o habitualmente en los dos últimos anteriores al testamento, ni la orden, convento o cofradia de que sea miembro el eclesiástico, ni sus deudos por consanguinidad o afinidad hasta el tercer grado inclusive".

"Pero esta incapacidad no comprenderá la iglesia parroquial del testador ni recaerá sobre la porción de bienes que el dicho eclesiástico o sus deudos habrian heredado abintestado, si no hubiera habido testamento"

Como se reconoce la capacidad existente a la fecha de entrada en vigencia de la ley, debemos entender que- en este caso - la parroquia tiene plena capacidad, pero la orden o convento del eclesiástico confesor no tiene plena capacidad. ¿Se considera vigente el artículo 965 después del artículo transitorio? ¿Y por qué sólo se aplica a eclesiásticos de la Iglesia Católica?

Otros problemas no previstos en la indicación Elgueta: ¿Los varios artículos del Código que se refieren a la parroquia son derogados tácitamente?

Por ejemplo, el artículo 586 del Código Civil regula la enajenación y administración de los bienes eclesiásticos de la Iglesia Católica: "Las cosas que han sido consagradas para el culto divino se regitán por el derecho canónico". Así, conforme al canon 1295 y 1296 del Código de Derecho Canónico y su legislación complementaria una enajenación de bienes de un valor no menor de 700 UF requiere autorización del Obispo Local y audiencia del interesado. Hasta 14.000 UF y más de 700 UF se requiere el permiso del Obispo y el consentimiento del Consejo de Asuntos Económicos y del Colegio de Consultores y el de los interesados. Este mismo consentimiento es requerido si el Obispo desea enajenar bienes de la diócesis. Sobre 14.000 UF se requiere además de licencia de la Santa Sede. La licencia de la Santa Sede se extiende al caso de la enajenación de bienes votivos o ex-votos donados a la Iglesia y a bienes preciosos por razones artísticas e históricas. ¿Se considera vigente este artículo 586 que remite al derecho canónico?

Las dudas respecto a la vigencia de estos artículos derivan de que el artículo transitorio aprobado por la Cámara, habla sólo de personalidad jurídica y de "capacidad de obrar", pero no habla del ordenamiento propio de iglesias, ni de su régimen jurídico como lo tienen reconocido en Chile la Iglesia Católica Romana y la Ortodoxa, esta última por ley de 1972. 
En sintesis: En el comienzo de toda la ambigüedad que suscitaba este artículo existe una introducción de un cuerpo normativo extranjero, hecho por una mezcla de liviandad e ignorancia.

\section{2.- LA AMBIGÜEDAD EN LA COMISIÓN ESPECIAL DEL SENADO. SEGUNDO TRÁMITE CONSTITUCIONAL.}

Para examinar este proyecto el Senado estableció una Comisión Especial compuesta de 11 Senadores presididos por don Mario Ríos. Esta Comisión aprobó en general el proyecto, incluyendo el artículo transitorio proveniente de la Cámara.

Sin embargo, se presentaron numerosas indicaciones destinadas todas ellas a dejar fuera de la ley a la Iglesia Católica y a la Iglesia Ortodoxa (Senadores Muñoz Barra, Bitar, Hamilton, Larraín, Diez, Piñera, Letelier, Feliú). Se buscaba, entonces, dejar en claro lo que contenía expresamente el Mensaje del Presidente Aylwin.

Si bien, todas estas indicaciones fueron rechazadas, el 29 de julio de 1997 prosperó una indicación refundida de los Senadores Diez-Piñera-Hamilton, aprobada por la unanimidad de la Comisión y del siguiente tenor: "artículo $6^{\circ}$, El Estado reconoce el ordenamiento, la personalidad jurídica de derecho público y la plena capacidad de goce y ejercicio de las iglesias, confesiones e instituciones religiosas que gocen de ella a la fecha de publicación de esta ley, cuyas normas no serán aplicables a las personas juridicas a que se refiere el inciso segundo del artículo 547 del Código Civil". (Segundo Informe de la Comisión especial, páginas 85 y 86). Aprueban este texto los senadores Cantuarias, Diez, Errázuriz, Horvath, Letelier, Núnez, Ríos, Ruiz de Giorgio, Sule y Zaldívar (don Andrés).

Como puede verse esto eliminaba toda ambigüedad y volvía, en mejor medida, al texto primitivo del proyecto Aylwin y era concorde con el proyecto Frei Bolivar - Ríos Santander de 1993.

Sin embargo, el 12 de agosto de 1997: "Se reabrió el debate, entre otros, en relación al artículo $6^{\circ}$ nuevo. El H.Senador señor Andrés Zaldivar afirmó que "el precepto podría dar lugar a interpretaciones que le imputaran discriminar arbitrariamente $y$, por lo tanto, provocar problemas de constitucionalidad" (Informe citado, página 86 del Segundo Informe de la Comisión Especial).

Siempre quedará en la duda si este copernicano cambio de la Comisión Especial se debió a una genuina duda jurídica o a una presión sobre los parlamentarios de parte del Comité de Organizaciones Evangélicas.

En efecto, en Carta del Comité de Organizaciones Evangélicas de 25 de agosto de 1997 a sus Iglesias Hermanas y Amigos en el Exterior se lee: "No obstante, nos preocupamos mucho cuando a la medianoche de la última noche de trabajo de la Comisión Especial fue escuchada una modificación presentada y aceptada a petición de la Conferencia Episcopal de Chile, por la cual se excluía a la Iglesia Católica de esta ley. Inmediatamente tomamos contacto con los Senadores 
más importantes del la Comisión Especial, les explicamos el problema y tuvimos éxito al obtener los votos necesarios para eliminar la modificación que excluía a la Iglesia Católica del texto final que la Comisión enviara a la Sala del Senado".

La hipótesis de la presión es plausible ya que el uso del "voto evangélico" como arma de convencimiento de parlamentarios fue constante durante todo el proyecto (Véase por ejemplo las declaraciones de don Francisco Anabalón, Moderador del Comité de Organizaciones Evangélicas en La Segunda del jueves 17 de septiembre de 1998. "Habrá instrucciones electorales para los evangélicos"... "sólo los partidarios de la más amplia libertad e igualdad religiosa recibirán nuestros votos". El propio coordinador reconoce alli que hubo una circular interna para las elecciones parlamentarias de 1998 y "a futuro seguiremos dando instrucciones electorales" refiriéndose a las elecciones presidenciales de 1999.

Producto de esta reapertura de debate se llega a un nuevo artículo $6^{\circ}$. El artículo $6^{\circ}$ de la Ley de Iglesias, aprobado entonces en la Comisión Especial, dirá: "El Estado reconoce el ordenamiento, la personalidad jurídica y la plena capacidad de goce y ejercicio de las iglesias, confesiones e instituciones religiosas que los tengan a la fecha de la publicación de esta ley, entidades que mantendrán el régimen jurídico adquirido con anterioridad a ella.".

Este artículo no hubiere planteado problemas si se le hubiere interpretado como habitualmente se lo hace con la Iglesia Católica, a saber que el estatuto jurídico de la Iglesia Católica en Chile es el de una persona jurídica de derecho público (conforme al artículo 547, inciso segundo del Código Civil), recepcionada constitucionalmente por el artículo $10 \mathrm{~N}^{\circ} 2$ de la Constitución de 1925. Su organización bajo la República se establece por ley de 24 de agosto de 1836.

Tal recepción constitucional en 1925 deriva del texto que dice: "Las iglesias, las confesiones e instituciones religiosas de cualquier culto, tendrán los derechos que otorgan y reconocen, con respecto a los bienes, las leyes actualmente en vigor. Ello se refuerza en el artículo $72 \mathrm{~N}^{\circ} 16$ y la disposición primera transitoria de la Constitución de 1925.

Dicha interpretación sostiene que la Iglesia Católica, después de la Constitución de 1925, seguirá rigiéndose por la ley Canónica.

Por eso, el 20 de septiembre de 1925, todos los Obispos Católicos afirmaron en Carta Pastoral, sin desmentido u observación alguna del Gobierno de Chile: "Pasando a lo temporal, la nueva Constitución no innova en el reconocimiento ni en la organización de la personalidad jurídica de que gozaba la Iglesia Católica bajo el imperio de la Constitución de 1833 y de las leyes existentes en el momento de su reforma. Por el contrario, en el artículo destinado a las garantías individuales se expresa que las iglesias, confesiones o instituciones religiosas de cualquier culto tendrán los derechos que otorgan y reconocen, con respecto a los bienes, las leyes actualmente en vigor, con lo cual las respectivas leyes han quedado, por decirlo así, 
incorporadas en la Constitución del Estado, estableciéndose un statu quo que no podrá ser alterado sin reforma de la Carta Fundamental".

Pero a corto andar, el artículo $6^{\circ}$ aprobado en la Comisión Especial va a ser entendido como una situación de facto: La Iglesia Católica en el país, no tendría ni personalidad jurídica ni menos derechos como entidad de Derecho Público.

Tal injustificada pretensión de los defensores del proyecto se deriva de las expresiones del Senador Andrés Zaldívar en la discusión general en la Sala del Senado. Allí se omite toda referencia al Derecho Canónico y, al contrario de la unanimidad de la doctrina y la jurisprudencia chilena, se interpreta de la siguiente manera por el Presidente actual del Senado el artículo 547, inciso segundo del Código Civil: "Hoy cumplimos una tarea que el gran Andrés Bello nos encargó hace más de 150 años. En efecto, el artículo 547 del Código Civil estatuye que las disposiciones del título a que él corresponde no se extienden "a las corporaciones o fundaciones de derecho público" como "las iglesias, las comunidades religiosas". Y agrega: "estas corporaciones y fundaciones se rigen por leyes y reglamentos especiales".

"Sin embargo, a pesar de la claridad de nuestro Código Civil, el tema de la naturaleza jurídica de las iglesias ha llegado a ser muy discutido en la jurisprudencia. En parte, esto ha estado relacionado con varios hechos históricos que afectaron las relaciones de las iglesias con el Estado chileno. Pero, fundamentalmente, el debate ha existido por una razón simple: porque, aún cuando el citado artículo 547 establece que las corporaciones y fundaciones se regirán por leyes especiales, el Estado chileno y sus legisladores nunca han dictado una ley para reconocer la naturaleza especial de la situación jurídica de las iglesias."

El garrafal error del Senador Zaldívar radica en no percatarse que jamás el artículo 547, inciso $2^{\circ}$ del Código Civil, en 150 años de jurisprudencia y práctica judicial y administrativa chilenas ha sido aplicado a otra iglesia que a la Iglesia Católica $y$, en consecuencia, se ha entendido siempre que respecto a ella no era necesario dictar una ley especial, pues el Estado de Chile desde siempre ha considerado que la legislación especial aplicable a la Iglesia Católica es el Derecho Canónico. No hay entonces tal vacío, ni un encargo no cumplido como pretende uno de los principales promotores del proyecto, que dio lugar a la llamada "Ley de Cultos".

En consecuencia: las asociaciones integrantes de la Iglesia Católica adquirieron su personalidad jurídica "en conformidad a la ley", esto es, en conformidad al Derecho Canónico y es esa personalidad la que, de acuerdo al artículo 547, inciso segundo del Código Civil es recepcionada como persona jurídica de derecho público por el derecho del Estado de Chile. Por ende, la superposición al Derecho Canónico de una ley especial del Estado chileno no sólo viola la separación de la Iglesia y el Estado, sino que atenta contra el artículo $19 \mathrm{~N}^{\circ}$ 5 , inciso segundo pues aplica a esta Iglesia Católica, no la ley que le corresponde de 
acuerdo a su naturaleza, sino una ley que se conforma a la arbitrariedad del legislador común.

Al interpretar así la situación de la Iglesia Católica, el Presidente del Senado dio adhesión a la tesis del Comité de Organizaciones Evangélicas el que a través de su asesor jurídico sostiene la opinión de una mera situación de hecho de la Iglesia Católica en el país. (Véase Alberto Rabah en el Diario Evangélico "Capítulo 30": octubre de 1997. Esta tesis ha sido defendida ampliamente por la asesoría jurídica del Comité de Organizaciones Evangélicas. Véase, por ejemplo, lo que alega el abogado Alberto Rabah en un escrito en el juicio de la Parroquia de Colina contra la Corporación de la Iglesia de Dios, rol 919 - 96: "Al no haberse dictado una ley o decreto con fuerza de ley que señala taxativamente el tipo de personalidad jurídica de la Iglesia Católica de Chile, forzoso es concluir, que ésta no ha tenido ni tiene en la actualidad personalidad jurídica en Chile, puesto que tampoco tiene personalidad jurídica de derecho privado"... "Pretender que pueda existir una personalidad jurídica de derecho público de hecho, o con un asiento en la costumbre o tradición, simplemente constituye tal aberración jurídica que debiera a lo menos llevarnos a preguntar si existe a este respecto el Estado de Derecho en Chile".

Así entonces, el artículo sexto aprobado era vaciado de contenido por el Presidente del Senado y por el abogado del Comité de Organizaciones Evangélicas, en desmedro de los derechos de la Iglesia Católica.

Este desconocimiento radical de la existencia jurídica y de los derechos de la Iglesia Católica en Chile claramente constituye no sólo un disparate -no sostenido ni por los juristas más contrarios a dicha Iglesia en sus comentarios a la Constitución de 1925- sino un abierto insulto, ya que se dice que ella usa y abusa de una posición contraria al Estado de Derecho. Por ello en noviembre de 1997 señalé en una conferencia cuando aún no pasaba el proyecto a examen de la Comisión de Constitución del Senado: "Es evidente que la Iglesia Católica no puede aceptar que perdure esa ambigüedad substancial y exige de los órganos co-legisladores dictar un texto claro, puesto que lo que está pasando con este proyecto es que de ser un proyecto que favorece a las Iglesias ha pasado a ser un proyecto contra la Iglesia Católica, en que el principal objetivo es someter a la Iglesia Católica a un cauce jurídico único, aunque se distorsione su naturaleza y su historia, aunque se actúe contra la expresa voluntad de toda su Jerarquía" ("Un caso de mutación legislativa: La Ley de Iglesias" en Humanitas, Separata VII, enero - marzo 1998, página 15).

No son los únicos testimonios para demostrar este esfuerzo por introducir a través de la ambigüiedad de un texto de consenso el contrabando ideológico que pretende probar la presunta desnudez jurídica de la Iglesia Católica en el país.

El cientista político Abraham Larrondo escribe en el periódico evangélico: Capítulo 30, en julio de 1999: "En otro orden, es necesario aclarar a la opinión pública que si a lo largo de la historia de Chile la Iglesia Católica Romana ha gozado de ciertos privilegios, ello ha sido también por la influencia y el poder político. 
Todo esto no exento de los abusos de autoridad que la han sostenido en nuestro país... Digamos la verdad al país: La Iglesia Católica Romana no tiene existencia legal en Chile. Es una institución religiosa cuyo origen es de facto y tal status jurídico no ha sido modificado en más de 70 años. No hay ley orgánica que diga lo contrario. De ahí que cualquier legislación de naturaleza religiosa afecta su condición jurídica y como tal condición le es conveniente para sus fines corporativos, puesto que nada la rige, asume una posición ecléctica y crítica frente a la ley de culto" (página 5).

Curiosa manera como se decía en los días de tramitación del proyecto de "no tocar a la Iglesia Católica ni con el pétalo de una rosa", como lo afirmaba en el Senado el moderador Francisco Anabalón del Comité de Organizaciones Evangélicas.

Irá incluso más allá el Senador Zaldívar (cito sus palabras del Diario de Sesiones del Senado, sesión 50, en miércoles 14 de mayo de 1997, páginas 5896 y 5897): "El proyecto no hace otra cosa que acatar lo que expresamente establece la Constitución Política de la República en el $N^{\circ} 6$ del artículo 19. Este es el mismo principio por el cual en Chile se ha reconocido la personalidad jurídica pública de la Iglesia Católica, después de la separación de la Iglesia y el Estado en 1925. No queremos ni debemos cambiar esta situación de hecho, que ha demostrado ser muy práctica y factible por más de 70 años en Chile."

La inesperada e infundida posición del Senador Zaldivar contra los derechos de la Iglesia a la que pertenece incluso le llevará a olvidar las actas de la Comisión Ortúzar que él cita truncas, (Diario de Sesiones pág. 5897) omitiendo lo que es contrario a su peregrina tesis. Dice la Comisión Ortúzar en una expresa constancia que luego será capital en la solución de este incordio: "Tratándose, sin embargo, de la Iglesia Católica, este reconocimiento ha sido hecho por el propio Constituyente de 1925, especialmente en la disposición primera transitoria de la Carta que autorizó al Estado para entregar al Arzobispado de Santiago durante cinco años cierta suma de dinero para ínvertirla en las necesidades del culto de la Iglesia Católica en el país, y en el artículo 72, número 16 que señala entre las atribuciones especiales del Presidente de la República la de celebrar concordatos.".

No hay entonces una "situación de hecho" sino una clara expresión de un derecho de la Iglesia Católica reconocida al más alto nivel jurídico, esto es, al nivel de las mismas Constituciones de 1833, 1925 y 1980, y ya antes de 1833 en Constituciones y Reglamentos Constitucionales de la República, incluso por la misma junta del 18 de septiembre de 1810 pero al aprobar un reconocimiento de la personalidad de una Iglesia a la que no se nombra y que solo gozaría de una situación de hecho se está reconociendo la nada misma para la Iglesia Católica. 


\section{3.- LA AMBIGÜEDAD EN LA COMISIÓN DE CONSTITUCIÓN DEL SENADO.}

Por ello tanto el profesor José Luis Cea, como el suscrito levantamos variadas objeciones de constitucionalidad al proyecto y en noviembre de 1997, el 11 del mismo mes, el Senado envió el proyecto a la Comisión de Constitución de esa Corporación, gracias al esfuerzo del Senador Hamilton.

Examinada la constitucionalidad del artículo $6^{\circ}$, por 3 votos a favor (Senadores Larraín, Fernández, Sule) contra dos en contra (Diez y Hamilton), la Comisión declaró constitucional el artículo sexto que había sido objetado por numerosos académicos. Se solicitó informes a las Universidades de Chile, Católica de Chile, de Concepción, Gabriela Mistral, Adolfo Ibáñez y Católica de Valparaíso. La Facultad de Derecho de la Universidad de Chile envió dos informes, uno elaborado por los profesores señores Paulino Varas y Salvador Mohor y otro preparado por el profesor Francisco Zúninga. Los profesores de Derecho Constitucional consultados a título individual fueron la señora Angela Vivanco y los señores Raúl Bertelsen, Guillermo Bruna, José Luis Cea, Francisco Cumplido y Alejandro Silva Bascuñán.

El Senador Larraín, (Presidente de la Comisión) al hacer la relación "agregó que los informes que se solicitaron a las Universidades y catedráticos - casi sin excepción - señalan que este proyecto, según el texto aprobado por la Comisión Especial, desconoce derechos esenciales de la Iglesia Católica, que los tendría con anterioridad a esta ley y que le son reconocidos por nuestro ordenamiento constitucional" (Informe de la Comisión de Constitución, página 20).

Sin embargo, la comisión por mayoría de votos, no acogió la opinión de los Constitucionalistas y lo lógico hubiere sido, entonces, conservar el texto de la Comisión Especial, si se entendía éste como constitucional. Pero no fue eso lo que hace la Comisión de Constitución.

La Comisión de la Constitución dice en la página 35 de su informe: "... el proyecto en estudio no adolece de vicios de constitucionalidad. No obstante lo anterior, con el objeto de perfeccionar la redacción de algunas de sus disposiciones $y$, como reiteradamente se ha expresado, con el espíritu de subsanar las razonables dudas de constitucionalidad surgidas durante el debate de este proyecto - que motivaron a la Sala formular la consulta que ahora absolvemos - os propone aprobar el proyecto de ley contenido en el segundo informe de la Comisión Especial, sugiriéndoles introducirle las siguientes enmiendas: El artículo $6^{\circ}$ : se ubicaría, bajo epígrafe "Disposición final, como artículo 20, con el siguiente tenor: "El Estado reconoce el ordenamiento, la personalidad jurídica de derecho público y la plena capacidad de goce y ejercicio de las iglesias, confesiones e instituciones religiosas que los tengan a la fecha de publicación de esta ley, entidades que mantendrán el régimen jurídico que les es propio". 
"Las iglesias, confesiones e instituciones religiosas que se constituyan con posterioridad a la entrada en vigencia de la presente ley, se regirán por ésta. Las actualmente existentes podrán optar, en cualquier momento, por someterse a las disposiciones de esta ley".

\section{4.- LA AMBIGÜEDAD EN LA SALA DEL SENADO. SEGUNDO TRÁMITE CONSTITUCIONAL.}

Enfrentada la Sala del Senado a tener que votar entre el artículo $6^{\circ}$ de la Comisión Especial y el nuevo artículo 20 propuesto por su Comisión de Constitución se trabajó para llegar a una solución de compromiso que dejara contentos a los "tirios" pentecostales que apoyaban el primitivo artículo $6^{\circ}$ y a los católicos "troyanos" que no lograban dejar nominativamente establecidos los derechos de su Iglesia.

En la Sala del Senado se presentó una indicación, suscrita por unanimidad de los Comités, destinada a modificar el artículo 20 de la Comisión de Constitución, Legislación y Justicia y del siguiente tenor: "El Estado reconoce la personalidad jurídica - sea ésta de derecho público o de derecho privado -, el ordenamiento y la plena capacidad de goce y ejercicio de las iglesias, confesiones e instituciones religiosas que los tengan a la fecha de publicación de esta ley, entidades que mantendrán el régimen jurídico que les es propio, sin que ello sea causa de trato desigual entre dichas entidades y las que se constituyan en conformidad a la presente ley".

Es absolutamente claro que esta redacción es contradictoria en sus mismos términos. En efecto, si se reconoce que hay iglesias con personalidad jurídica tenida en conformidad al DS 110 de Justicia e iglesias con personalidad juridica de Derecho público el reconocimiento de esta realidad plural significa desde ya un tratamiento diferenciado y desigual entre ellas. Así entonces, había que entender que la declaración final es para dejar de manifesto que pese a reconocer un régimen plural, tal pluralidad "no es causa de trato desigual".

Es ambigua, tanto porque las iglesias con personalidad jurídica de pleno derecho público son prácticamente las únicas que tienen un régimen juridico propio que se ha ido constituyendo a través de la historia, como en especial porque de la redacción podría aparecer que el reconocimiento es bajo la condición que ello no signifique trato desigual.

Ahora bien, ello significaría que no hay tal reconocimiento porque si a futuro las nuevas iglesias que se constituyan son desiguales frente al Estado: ¿significa que las antiguas hoy reconocidas deben igualarse a las nuevas? ¿O significa que las nuevas no podrán ir más allá que las antiguas debiendo igualarse a las segundas como entidades paradigmáticas? ¿Dónde queda entonces la libertad religiosa? 
Parecería que el legislador borra con el codo de su frase final lo que escribe en el corpus de su artículo y curiosamente esta redacción es apoyada por el Senador Larraín, después de haberla recibida del abogado del Comité de Organizaciones Evangélicas.

Ahora bien, en el caso de la Iglesia Católica cuyo régimen jurídico ha sido reconocida en sede constitucional y en el caso de la Iglesia Ortodoxa cuyo régimen jurídico ha sido reconocido en sede legal, pero con claro amparo constitucional, la norma legal de su nuevo reconocimiento es de mera certeza jurídica.

No podría ahora el legislador simple colocar nuevas condiciones al reconocimiento ya efectuado, sin violar la Constitución y en este sentido debe entenderse que a nadie corresponde calificar de desigual el trato plural señalado por la propia Carta Fundamental.

Así las cosas, la frase final es tan contradictoria y ambigua que merece tenerse por no escrita, a menos que se interprete como un "descargo de conciencia" de los parlamentarios que de mala gana reconocen a la Iglesia Católica en sus derechos históricos, pero agregan para la galería evangélica de sus electores "sin que ello (el reconocimiento) sea causa de trato desigual entre dichas entidades y las que se constituyan en conformidad a la presente ley".

No se diga que el Senado actuó sin advertencia.

Dijo el Senador Valdés, quien votara en definitiva en contra del artículo: "Se ha llegado a una fórmula que no me satisface. Yo habría preferido algo claro como lo es el antiguo artículo 20, que apoyo y fortaleceré con mi voto si es necesario escoger entre dos. Me parece que es nítido. Distingue dos situaciones que en nada hacen desmerecer lo que se está dando por la ley a las iglesias evangélicas: estatuto de derecho público, garantías de todo orden, significación protocolar. Se ha hablado de los privilegios o derechos de que goza la Iglesia Católica: también disfrutarán de ellos. No hay distinción de especie alguna en Chile... En cambio, me parece contradictoria la frase que algunos señores Senadores han propuesto agregar: "sin que ello sea causa de trato desigual entre dichas entidades y las que se constituyan en conformidad a esta ley"... Contradice, en efecto, lo señalado antes en cuanto a que "mantendrán el régimen jurídico que les es propio".

"La contradicción es evidente y considero fundamental que la nueva ley no contenga ninguna disposición ambigua. Debe ser absolutamente clara. Es un esfuerzo para determinar la coexistencia de dos elementos nítidos: la existencia de iglesias que poseen derechos establecidos y la decisión unánime del Senado - así lo espero - en cuanto a disponer que las iglesias que no tienen tales derechos los tendrán igualmente en virtud de la ley en proyecto".

"Empero, la frase que he mencionado y que hace referencia a "trato desigual", introduce, a mi juicio, un factor de discusión. En esta materia, señor Presidente,"opino que la situación es muy delicada; el problema, muy de fondo; la 
intención muy clara. No hay necesidad de buscar cosas oscuras. Estoy lejos de pensar que hay envuelto aquí un interés electoral".

El Senador Chadwick se abstuvo con justas razones: "La redacción del artículo 20 que plantea la indicación puede llevar a una incorrecta interpretación en cuanto a contrariar el sentido de la plena igualdad consagrada en el Texto Fundamental. Y, en esa perspectiva, de ser esa interpretación la que pueda prevalecer en el futuro, esta disposición sería inconstitucional, porque estaría planteando un concepto de igualdad distinto del consagrado por la Constitución Política".

"Me hubiera gustado haber hecho a través de la indicación las cosas en forma más simple, directa y obvia. Si todos pensamos, que ella debe entenderse en el sentido del artículo $19 \mathrm{~N}^{2} 2$ : por qué no utilizamos el lenguaje que el propio Constituyente empleó en esta norma, y habríamos establecido que no puede haber diferencias arbitrarias o trato discriminatorio. Porque los elementos señalados por el Constituyente están ahi, en la Carta Fundamental".

"Y nos merece dudas cuando todos dicen seguir el espíritu de la Constitución y que debemos entender e interpretar la norma en el sentido señalado en el artículo $19 \mathrm{~N}^{\circ} 2$, pero no utilizamos el lenguaje que se encuentra a nuestra disposición y que sólo basta transcribir del propio Texto Constitucional". (Sesión 10a , en martes 6 de julio de 1999, página 1.081).

La ambigüedad aumenta si se atiende a la constancia que aparece en las páginas 1.097 y 1.098 del Diario de Sesiones del Senado ya citado: "El proyecto que hoy aprueba el Senado tiene como propósito permitir que las iglesias, confesiones e instituciones religiosas que así lo deseen, puedan constituirse con igual personería jurídica de derecho público, por el solo hecho de seguir los procedimientos que establece esta iniciativa legal".

En primer lugar, la constancia da a entender que esta ley es un cauce optativo para las iglesias que así lo deseen. Ello, sin embargo, no tiene ningún asidero explícito en el texto de la ley. En parte alguna se regula ese presunto derecho de opción. Parecería que la palabra "mantendrán" del artículo 20 aprobado (y no "podrán mantener") exige sólo de las actuales iglesias que conserven su presente situación jurídica, sea ella de derecho privado o de derecho público, y que las iglesias que se constituyan en el futuro deberán regirse por la presente ley. Pero ello es absurdo respecto de las iglesias regidas actualmente por el DS 110, al menos las evangélico - pentecostales, que precisamente han solicitado un nuevo estatuto jurídico. Es también absurdo respecto de la Iglesia Católica y de la Iglesia Ortodoxa que no pueden, aunque lo deseen, cambiar unilateralmente su régímen jurídico reconocido por el Estado en sede constitucional y en sede legal, respectivamente, y pactado con ellas.

En segundo lugar, la constancia da a entender que todas las iglesias tienen igual personería jurídica de derecho público. Sin embargo, ello no es real. 
La Iglesia Católica Romana y la Iglesia Ortodoxa gozan de una efectiva personalidad jurídica de derecho público para todas sus personas canónicas, no cancelable por sentencia judicial y que no puede disolverse sino en virtud de acuerdo con el Estado y en la misma sede jurídica en que se reconoció, sin perjuicio que para ellas mano alguna humana puede disolver lo que Cristo instituyó.

Por el contrario, las iglesias que se constituyan en conformidad con esta ley gozan de personalidad jurídica especial y pueden además establecer corporaciones, fundaciones y asociaciones en su seno de acuerdo al artículo 9, con personalidad jurídica religiosa de derecho público, todas las que pueden ser disueltas por sus integrantes o por sentencia judicial de acuerdo al artículo 19.

Ello tampoco escapó al Senador Valdés (Diario de Sesiones, citado, página 1.063): "Señor Presidente quiero hacer una aclaración respecto al artículo 17, que ha pasado a ser 19. Esta norma se refiere a la disolución de una persona jurídica, la cual puede llevarse a cabo conforme a sus estatutos o en cumplimiento de una sentencia judicial firme, recaída en juicio incoado a requerimiento del Consejo de Defensa del Estado. Me preocupa lo anterior, porque encuentro un poco contradictoria la persona jurídica de Derecho Público que puede ser disuelta por sentencia judicial. Sería una persona de Derecho Público híbrida".

"Es comprensible que sus estatutos contemplen la forma en la que será disuelta, lo cual me parece muy bien, pues son asociaciones voluntarias y no de Derecho Público, como el Estado u otras, que no pueden ser disueltas sino por ley. En este caso, evidentemente, es factible hacerlo por voluntad propia".

"Pero no me parece apropiado que una entidad religiosa, reconocida como tal y que goza de una personalidad jurídica de Derecho Público, sea disuelta por un tribunal ante el reclamo de alguien".

El señor Zaldívar (don Adolfo) ¡No es persona de Derecho Público!

El señor Valdés: Si fuera persona jurídica de Derecho Público, tendría que cumplir sus finalidades. Prefiero el respeto que conlleva la personería jurídica de Derecho público, sin riesgos de una acción que la pueda destruir. No es conveniente exponer a las iglesias, de cualquier denominación, al riesgo de que en un momento dado prospere una acción judicial que implique liquidarlas".

Ello no es lo que, contra toda lógica, sostiene el senador Larraín: "Por razones de carácter histórico, no todos los credos religiosos que funcionan en nuestro país han tenido el mismo reconocimiento jurídico de nuestra legislación. Es así como se ha dicho que la Iglesia Católica o la Iglesia Católica Apostólica Ortodoxa de Chile gozan, por distintas consideraciones, de personalidad jurídica de Derecho público. Por eso, mientras otras no la tienen, este proyecto procura establecer, desde este punto de vista, la igualdad jurídica entre las iglesias que existan y las que puedan constituit conforme a la iniciativa en estudio". "Por lo tanto, su aplicación y consecuencia natural apunta a que todas las entidades religiosas que se constituyan en lo sucesivo, de acuerdo con los procedimientos que 
establece esta normativa y una vez que haya sido promulgada-, adquirirán ante la ley el mismo status, el mismo reconocimiento legal en su personalidad jurídica" (ibidem, página 1069)... "Porque si se mantuviese el régimen de las iglesias que ya tienen su situación configurada conforme a la legislación vigente, podría entenderse que ellas poseen algún privilegio o grado de exclusividad del cual carecen las que se constituyan de acuerdo con las nueva norma. Allí es donde se ha producido la inquietud y la diferencia" (página 1070).

La contradicción y ambigüedad se traslada a las personas creadas por las iglesias, revelando la intervención del Senador Larraín una ignorancia en la recepción de las personas canónicas de la Iglesia Católica en el ordenamiento interno chileno: "Hoy día, la Iglesia Católica crea entes - sea a través de una parroquia, una congregación u otra institución - mediante los cuales pueda expresarse y cuya personalidad jurídica es religiosa; vale decir, no constituyen una personalidad juridica separada. No necesitan hacerlo de acuerdo a la legislación vigente, por cuanto ya se encuentra constituida la respectiva personalidad jurídica, la cual es reconocida por nuestra legislación".

Continuará el Senador Larraín: "A través de este artículo se pretende precisar que las iglesias que se establezcan en virtud de la presente normativa podrán también hacer lo propio en el futuro. Esto implica que si ellas se constituyen conforme a esta ley - sean de cualquier denominación - musulmana o judía - , podrán crear personas jurídicas religiosas vale decir, se benefician de la misma personería que tiene la Iglesia Madre, sin que para eso deban recurrir a la legislación vigente". (sesión 10a, en martes 6 de julio de 1999, citado, en página 1061).

Pero, como ya está explicado la ley dejó abierto tres cauces jurídicos: el DS 110, de Justicia; el régimen privativo de la Iglesia Católica y el de la Iglesia Ortodoxa, ambas con personalidad de derecho público y el régimen de esta ley con sus entidades de personalidad jurídica religiosa especial que por razones ideológicas, no exentas de demogogia electoral, llámase de Derecho Público.

La interpretación de los comentaristas evangélicos resalta la ambigüedad de lo aprobado. Así escribe Abraham Larrondo Vega, cientista político evangélico, en el número 62 de "Capítulo 30" septiembre de 1998, página 5: "Si bien con esta ley concluye una etapa importante del debate sobre igualdad religiosa, posterga la aspiración de los evangélicos - de alcanzar plena igualdad con la relígión Católica y Ortodoxa porque fue imposible convencer a los legisladores que en un país democrático simplemente no debe existir privilegio de ninguna especie. Hoy en día la Iglesia Católica ha reafirmado su patrimonio jurídico sobre la base del llamado "derecho de arraigo" - que no es otra cosa que el reconocimiento a su larga y angustiosa trayectoria histórica - en el desarrollo de las instituciones de Chile. En oposición a ello, a las corporaciones evangélicas se les ha reconocido un "derecho de existencia", que si bien les permite acceder a un status jurídico de derecho público, las distingue de las confesiones tradicionales, en cuanto a vulnerabilidad de 
sus instituciones, que en la eventualidad de que se produzcan determinadas irregularidades, el Consejo de Defensa del Estado podría - previa investigación derogar, suspender o sancionar la entidad cuestionada. Lo cual - naturalmente - no ocurriría con las iglesias católicas y ortodoxas, que están sujetas a fuero en un régimen jurídico distinto al de otras confesiones religiosas, que no viene al caso analizar". (agosto de 1999).

\section{5-. LA AMBIGÜEDAD EN LA CÁMARA DE DIPUTADOS. TERCER TRÁMITE CONSTITUCIONAL.}

El debate del proyecto en la Cámara incrementó la zona de incertidumbre. Los diputados, en primer lugar, hicieron caso omiso de la constancia senatorial tan laboriosamente "trabajada" por los senadores Ríos, Larraín y Andrés Zaldivar.

En realidad la famosa "constancia" que solucionaría todos los problemas no es parte de la historia fidedigna de la ley como pretenden sus autores ya que excede el texto de la ley aprobada. Es un gesto político - ideológico de los firmantes, algunos de los cuales, querían dejar un testimonio de progresismo político y ottos aligerar su responsabilidad como católicos.

Ello no escapó a la Cámara de Diputados, en tercer trámite constitucional.

El diputado Elgueta, ya citado al comienzo de este trabajo, dice en tanto informante del proyecto: "Hago un paréntesis en mi intervención para señalar que cuando esta ley esté promulgada y publicada en el Diario Oficial, su texto se independiza de aquellas constancias de aquellas actas que particulares quieran introducir de acuerdo con sus opiniones en los distintos tramos legislativos".

El señor Cornejo afirmó: "El artículo $3^{\circ}$ del Código Civil señala que sólo toca al legislador, de manera obligatoria, interpretar la ley. El proyecto despachado por el Senado, al final, deja una constancia que sólo tiende a interpretar el artículo 20 aprobado por esa rama del Congreso".

"En consecuencia, al menos en términos personales, quiero señalar que no es un buen método legislativo interpretar normas aprobadas por el propio Senado, por la vía de una constancia en la iniciativa, porque, como lo expresa el Código Civil, debiera hacerse a través de una ley. Por lo tanto, reitero que no es un buen sistema dejar constancia o explicar un texto aprobado con el objeto de que el día de mañana se constituya en un elemento de interpretación en el caso de surgir alguna controversia. De manera que me parece importante dejar establecido que al legislador le corresponde hacer esa interpretación sólo por ley, como dice el Código Civil, y no por la vía de una constancia que no forme parte del cuerpo normativo que la Cámara despachará hoy". (Cámara de Diputados, sesión 20, en jueves 15 de julio de 1999, publicación oficial, Redacción de sesiones, páginas 23 y 24).

Lo propio hará el diputado Letelier: "Esta etapa en que estamos es de tremenda importancia y, por lo mismo, es necesario emitir un juicio sobre la 
constancia que se entregó en el Senado respecto del artículo 20. En lo personal, no me parece un método correcto de legislar, menos aún cuando la Corporación entera participa de una constancia que pudiese ser mal entendida o mal interpretada en el futuro. Quiero dejar establecida nuestra opinión. Lo que vale es lo que aprobaremos en el artículo 20 en la letra y en el espíritu, y no debe tratarse de dar otras interpretaciones en caso de conflicto en el futuro" (citado, página 30). Guzmán.

Sin embargo, ello no fue compartido por los diputados Zarko Luksic y Pía

El primero pretende aclarar el texto ambiguo del artículo 20: "Se ha tenido la conducta concordante en el sentido de no afectar o desconocer el estatuto jurídico de derecho público, que tienen la Iglesia Católica y la Iglesia Ortodoxa de Antioquía.

El Senado en este sentido, ha buscado despejar cualquier duda al respecto. Para ello es conveniente poner atención en la disposición que modifica el artículo transitorio en la versión de la Cámara de Diputados, artículo 20 bajo el epígrafe Disposición Final en la del Senado. Especial atención debe tener a este respecto la forma verbal en futuro que tiene en dicha disposición el verbo mantener, así como se explica por el informante de la Comisión de Constitución, Legislación, Justicia y Reglamento del Senado, senador Hernán Larraín". (página 40).

Sin embargo, el propio diputado Luksic ha dicho antes en el debate como muestra de las sinuosidades de la "solución" a la que se llegó: "En primer lugar, el proyecto es fruto de una larga e injusta espera. Como se ha señalado, la Constitución de 1925, al igual que la de 1980, establecía la garantía constitucional de la libertad religiosa de culto. Este proyecto de ley es el desarrollo de esa garantía constitucional, reiterada por la Carta Fundamental vigente. es decir, ha debido transcurrir más de 75 años para dar cumplimiento a un derecho fundamental establecido en nuestra Carta Magna. En segundo término, el estatus jurídico que se otorga a las iglesias, órdenes y fundaciones religiosas (sic) es de un carácter especial, es el de una personalidad jurídica de derecho religioso. Desde mi punto de vista, el estatus preciso no es la personalidad jurídica de derecho privado ni de derecho público, creada por una ley particular, pero posee todos los efectos jurídicos de una personalidad Jurídica de derecho público creada por ley". (página 32)

Por su parte, la diputado Pía Guzmán dirá: "Como legisladora, aunque signifique nadar contra la corriente, debo hacer presente, en conciencia, dos deficiencias que contiene el proyecto modificado por el Senado. Digo esto, porque el intérprete no es sólo la ley, como señalaba el diputado señor Aldo Cornejo, sino porque también hay una interpretación judicial, la que se realiza según las normas del Código Civil, donde se consigna la necesidad de dejar establecida una historia de la legislación... El artículo 20, nuevo, que consigna el Senado, es muy importante en cuanto reconoce el ordenamiento y la personalidad jurídica de derecho público de las iglesias reconocidas por el Estado". 
"Pero, para la interpretación de la ley, dicho reconocimiento no implica un trato desigual, concepto poco utilizado en el lenguaje jurídico. Por lo tanto, siempre debe ser entendido a la luz de los derechos garantizados en la Constitución, de manera específica en el inciso segundo del número 2 del artículo 19, según el cual "ni la ley ni autoridad alguna podrán establecer diferencias arbitrarias". (Diario de Sesiones, sesión 20, en jueves 15 de julio (le 1999, página 33).

Cuando se examina, por lo tanto, el debate de la Cámara en tercer trámite constitucional se ve que el ambiguo texto aprobado en el Senado con una amplísima y trabajosa constancia es interpretado en el hemiciclo de la Cámara Baja en forma dispar y se desconoce por varios diputados la "constancia" de los Senadores. ¿Cuál será entonces la historia fidedigna?

No hay otra en este proyecto que: la historia de la ambigüedad utilizada ideológicamente para dar una apariencia de acuerdo y consenso, alli donde en realidad, pese a los abrazos y auto complacencias de tirios y troyamos en las galerías del Senado, reinan las diferencias y desconfranzas.

\section{A MODO DE EPÍLOGO}

A corto andar e incluso antes de publicada la ley sobre iglesias las diferencias aparecieron. De los sectores evangélicos las preocupaciones fueron la posibilidad que sectas y empresas disfrazadas de entes religiosos utilizaran el marco de esta ley, dada su extrema laxitud. Así siguiendo lo que fue su principal preocupación durante la tramitación del proyecto, el abogado bautista Humberto Lagos Schuffeneger multiplicó sus intervenciones en los medios de comunicación en este sentido.

Así, por ejemplo, en La Segunda del martes 31 de agosto de 1999, sostiene que para cancelar la personalidad jurídica de una secta o entidad de lavado de dinero que se hace pasar por iglesia "se necesitarán elementos de prueba que son prácticamente imposibles de allegar" y que "mediante esta norma se obliga al Estado a renunciar a los controles que histórica, tradicional y legalmente ha ejercido en materia de las personas de derecho" (pág.6)

El diácono Enrique Palet, vocero de la Conferencia Episcopal señaló el jueves 26 de agosto en La Segunda que el Episcopado temía que conceptos vagos de la ley de culto lleven a un desprestigio de lo religioso (pág.47) y que "(la ley) entraña el peligro de que obtengan personalidad jurídica, por ejemplo, grupos parasicológicos, o de interés humanista o social o incluso grupos de mala fe que quieran lucrar y obtener beneficios".

Más aún, "la eliminación de las actuales clases de religión católica en colegios con financiamiento fiscal en que no se asegure la opción de una religión diferente a la católica" es propuesta por evangélicos como el Presidente de la Sociedad Bíblica de Chile (La Segunda, lunes 4 de octubre de 1999, página 18). 
En el centro de todo este debate está la ambigua redacción del artículo 20 de la ley y aunque la Iglesia Católica puede sentirse razonablemente satisfecha en periodo corto, el contencioso abierto por la Ley de Iglesias está lejos de haberse cerrado, lo que avisora lamentablemente nuevas dificultades.

Un resumen de mis prevenciones frente a la nueva Ley se encuentra en El Metropolitano de 19 de agosto de 1999, página 17; en la que en síntesis se lee: "El texto de la ley de iglesias aprobado por el Congreso Nacional es una mala respuesta legislativa a inquietudes legítimas de las entidades religiosas no católicas, un acuerdo parlamentario que puede llegar a debilitar a las Iglesias Católica y Ortodoxa, que crea un híbrido jurídico para las creencias no católicas y abre la puerta al abuso de personalidades religiosas por las sectas y religiones - empresa, estableciendo zonas de incertidumbre jurídica y posibilidades de intervenciones abusivas de órganos estatales en materia religiosa".

Concluía alli lo que jurídicamente yo informaba al Episcopado Nacional el mismo día en que el Senado aprobaba el proyecto de ley en segundo trámite constitucional, después de dos años de haber trabajado como el colaborador legislativo de los obispos católicos para estos efectos.

Recordaba entonces las palabras que el Nuncio de su Santidad, Monseñor Luigi Ventura pronunciara el domingo 25 de julio de 1999 en su homilía en la Solemnidad del Apóstol Santiago: "Sobre esta piedra edificaré mi Iglesia", anunciará Jesús después de la confesión de Pedro, quien antes había respondido a la pregunta sobre la identidad de Jesús, dirigida a todo el grupo de los apóstoles: "pero vosotros ¿quién decís que soy? (Mt.16,15).

Jesús dice: "Mi Iglesia"; no dice: "mis iglesias". "Una es, por tanto, la Iglesia por la que ha ofrecido su vida".

"Las varias comunidades cristianas, las varias diócesis del mundo, pueden decirse iglesia, sólo si vive en ellas la Santa Iglesia Católica, en la integridad de su doctrina, en la comunión plena de todos los pastores, que cuidan la verdadera fe transmitida por los apóstoles en el idéntico y generoso compromiso de amor hacia los hermanos, en el anhelo común de hacer conocer el Evangelio".

$\mathrm{Y}$ la experiencia vivida en una larga relación con parlamentarios, me hacia rememorar lo de Abdón Cifuentes: "Aquí como en casi todas las partes el mismo espectáculo: minorías bulliciosas y audaces dominando a mayorías mudas y egoistas, desunidas y dispersas".

"Así se explica que un país católico esté representado por Ministros incrédulos Diputados incrédulos, Gobernadores incrédulos y hasta por gendarmenes incrédulos y todos mas o menos enemigos de la Iglesia. He aquí los representantes que elige una nación Católica" (Memorias, Nacimiento, 1936, página 261).

Y cita a Cifuentes las expresiones de Montalmbert en el Congreso Católico de Malinas de 1863: "La vida pública, esta gloriosa herencia de las naciones adultas, 
este régimen de libertad y responsabilidad, que enseña al hombre el arte de confiar en si mismos es lo que más falta hace a los católicos modernos. Excelentes en la vida privada, de ordinario brillan por su ausencia y sucumben en la vida pública y están en todas partes supeditados, pospuestos, intimidados o vencidos por sus enemigos, sus adversarios o sus opresores: aquí por los incrédulos, allá por los protestantes, hoy por los demagogos, mañana por los déspotas".

"En la vida pública ser católicos es vivir ausentes y confiarse en Dios" (Memorias, obra citada, página 128). 